Med Klin Intensivmed Notfmed 2018 113:33-44 https://doi.org/10.1007/s00063-017-0369-7

Published online: 7 November 2017

(c) Springer Medizin Verlag GmbH 2017

CrossMark

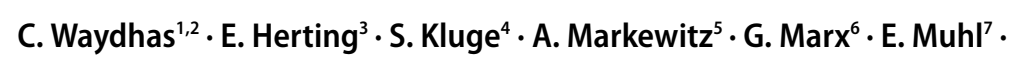
T. Nicolai ${ }^{8} \cdot$ K. Notz ${ }^{9} \cdot$ V. Parvu ${ }^{10} \cdot$ M. Quintel ${ }^{11} \cdot$ E. Rickels $^{12} \cdot$ D. Schneider ${ }^{13}$. K. R. Steinmeyer-Bauer ${ }^{14} \cdot$ G. Sybrecht ${ }^{15} \cdot$ T. Welte ${ }^{16}$

${ }^{1}$ Chirurgische Universitätsklinik und Poliklinik, Berufsgenossenschaftliches Universitätsklinikum Bergmannsheil, Bochum, Germany; ${ }^{2}$ Medizinische Fakultät, Universität Duisburg-Essen, Essen, Germany; ${ }^{3}$ Department of Paediatrics and Adolescent Medicine, Lübeck, Germany; ${ }^{4}$ Intensive Care Medicine, Hamburg-Eppendorf University Hospital, Hamburg, Germany; ${ }^{5}$ Unit XVII-Department of Cardiovascular Surgery, BwZK, Koblenz, Germany; ${ }^{6}$ Surgical Intensive Care Medicine and Intermediate Care, Uniklinik RWTH Aachen, Aachen, Germany; ${ }^{7}$ Interdisciplinary Surgical Intensive Care Unit, UKSH Campus Lübeck, Lübeck, Germany; ${ }^{8}$ v. Haunersches Kinderspital, Campus Innenstadt, Munich, Germany; ${ }^{9}$ Teaching Facilities, Akademie, Kreiskliniken Reutlingen $\mathrm{GmbH}$, Reutlingen, Germany; ${ }^{10}$ Deutsche Interdisziplinäre Vereinigung für Intensiv- und Notfallmedizin e.V., Berlin, Germany; "Centre for Anaesthesiology, Emergency and Intensive Care Medicine, Universitätsmedizin Göttingen, Göttingen, Germany; ${ }^{12}$ Neurotraumatology, Allgemeines Krankenhaus Celle, Celle, Germany; ${ }^{13}$ Internal Medicine, Neurology and Psychiatry, Department of Anaesthesiology and Intensive Care Therapy, Universitätsklinikum Leipzig AöR, Leipzig, Germany; ${ }^{14}$ Brühl, Germany; ${ }^{15}$ Deutsche Interdisziplinäre Vereinigung für Intensiv- und Notfallmedizin e.V., SIN mbH, Berlin, Germany; ${ }^{16}$ Department of Pneumology, MHH Hanover, Hannover, Germany

\section{Intermediate care units}

\section{Recommendations on facilities and structure}

The recommendations of the German Interdisciplinary Association for Intensive Care and Emergency Medicine (DIVI) on the capacity, equipment and structure of these units are intended to provide the framework for the setting up and operation of IMCs in collaboration with experts on both an evidence-based and an expert-based basis (where scientific evidence is not available). Where only minimal or indirect evidence is available, patient safety is paramount in the formulation of the recommendation. In the unanimous view of all DIVI representatives, this has the highest priority for those entrusted with intermediate care of critically ill and at-risk patients.

\section{Target group}

The recommendations on the structure and equipment on IMC apply to adult patients. The opinion of the German Society for Neonatology and Paediatric Intensive Care Medicine (GNPI) can be found in Appendix 1 (Electronic supplementary material).

\section{Definitions}

There has not yet been a generally or internationally binding definition of intermediate care or of an IMC. An IMC is intended to be a unit where those patients are treated that do not require the resources of intensive care unit (ICU), but are too ill or on too high maintenance for treatment on an SCU. The English definition of intermediate care, which refers to high-maintenance, usually elderly patients in transition from the inpatient to outpatient sector and corresponds best to short-term care (Kurzzeitpflege) in Germany, is explicitly not intended here.

It is important, therefore, to distinguish the IMC from both the ICU and the SCU:

\section{Definition of intermediate care unit}

The IMC is suited to the monitoring and treatment of patients with moderate or potentially severe instability of physiological parameters that require equipmentbased monitoring and organ support, but do not require organ replacement. This includes patients that require less than normal intensive care, but more than is 
possible on the SCU $[1,2]$. The IMC is not intended to replace an ICU. Of course, there may be overlaps between these two forms of unit; whether certain forms of organ support are provided on an IMC rather than on an ICU may depend on considerations such as those detailed below.

The task of the IMC is to care for patients whose treatment is so intensive and/or complex that they require constant or close monitoring. These are patients whose conditions suggest possible failure of one or more organs, or whose conditions are too serious or unstable after failure of one or more organs for a return to a SCU and who, therefore, require continuous monitoring. This includes prevention, diagnosis and treatment of all medical and surgical diseases that could lead to the failure of vital functions. The IMC also offers highly specialised treatment, such as neurological or cardiology treatment (stroke unit, coronary care unit, etc.), to ensure the best possible standard of treatment [3].

\section{Definition of intensive care unit}

The ICU is a specially equipped unit staffed by specialist personnel to ensure the medical care of critically ill patients [4]. The critically ill patient is characterised by life-threatening disorders of one or more body systems as a result of disease or injury:

- Cardiovascular function

- Respiratory function

- Central nervous system

- Neuromuscular function

- Kidneys

- Liver

- Gastrointestinal tract

- Metabolism

- Disorders of temperature regulation

- Haemorrhagic diathesis

\section{Definition of standard care unit}

An SCU is an area where the patients being cared for require the special resources of a hospital for a procedure or due to the severity of a disorder, but do not require constant monitoring (or support) of vital functions; in addition, patients do not require highly elaborate care and there is no concrete risk of a life-threatening or organ-threatening disorder.

\section{Distinction between intensive care unit, intermediate care unit and standard care unit}

It is evident from the above-mentioned definitions that there is a continuous spectrum of disease severity and treatment requirements in the crossover between the three units and a clear distinction is generally not possible. Among other factors, the allocation of patients to units also depends on the relevant structures and facilities and, thus, on the resources available to the hospital or unit.

For example, the personnel on the SCU and their qualifications (including night-time personnel), its technical resources (basic ECG monitoring, noninvasive blood pressure measurement, pulse oximetry with central monitoring and alarm function), structural layout (walking distances, audibility of alarms sounds, physician availability) and the experience of personnel (e.g. in handling special, intravenously administered drugs, recognising developing problems) have a significant influence on treatment options.

The crossover between intermediate and intensive care may be no less fluid. To which unit should non-invasive ventilation be assigned? Is invasive blood pressure measurement or the administration of catecholamines possible on an IMC? This distinction is extremely vague in the integrated organisation model (see "Organisational forms").

Therefore, it is necessary to define specific admission and discharge criteria.

In this context, the following criteria represent an assessment framework [1, 2]:

a. Impaired or threatened organ function

b. Specialised surgical procedures, conditions or disorders that carry the risk of developing a (potentially) threatening dysfunction and therefore require close monitoring

c. Specialised pathological findings or laboratory values d. Conditions requiring a high level of care

"Intermediate Care Unit" can be understood as an umbrella term for various labels or names that correspond to the above assessment framework. Such labels include:

- Coronary Care Unit/Chest Pain Unit

- High Dependency Care Unit

- Intermediate Care Unit

- Post-Anaesthesia Care Unit

- Step-Down Unit

- Stroke Unit

- Vascular Assist Device (VAD) Unit

The recommendations discussed below relate to a general IMC according to the above-mentioned inclusion and exclusion criteria for treatment on an IMC. These need be adapted to local requirements and conditions and the focus of each unit. If more extensive services are offered on an IMC, staffing and structural arrangements need to be increased according to requirements and, conversely, reduced for a less extensive range of services.

The procedure for developing the recommendations is detailed in the "Methods" section at the end of the manuscript. In general, there is scant scientific evidence relating to the structure and facilities of IMCs. Many recommendations are therefore based on interdisciplinary and interprofessional expert consensus (as set out below). A "1C" recommendation, for example, corresponds to a strong recommendation based on an expert consensus.

\section{General recommendations}

\section{IMC inclusion and exclusion criteria}

\section{Key statement}

Specific admission and discharge/transfer criteria need to be defined to regulate the transfer between the various levels of care (intensive care, intermediate care, standard care). These criteria (for admission to and transfer from an IMC) should be bindingly agreed in consultation with the adjoining units (1C). 
There is a consensus that each IMC should develop specific admission and transfer criteria $[1,5,6]$.

In addition to the general criteria for the admission or transfer of patients, specific criteria can be applied for certain units, which take into consideration the treatment of specific diseases (e. g. Stroke Unit, Coronary Care Unit) or treatment situations (e.g. Weaning Unit). These specific criteria (see Special Section) can directly affect the structure and facilities of the respective unit, which may lie above (or possibly below) the requirements of a general IMC.

\section{Organisation}

\section{Organisational forms}

\section{Key statement}

The organisational form recommended is either an integration model within an ICU or a parallel model adjacent to an ICU (with common management) or a stand-alone IMC. The choice of organisational form should be chosen according to local factors (1C).

Due to the particular factors in heart surgery, other organisational forms may also be considered and implemented [7]. A prerequisite of this is compliance with the personnel, equipment, layout and organisational requirements cited in this recommendation.

\section{Integration model in an intensive care} unit $[7,8]$. On a combined unit, intensive care and intermediate care patients are treated together. The formal allocation to one or other category is made using a list of criteria. The advantages here lie in extremely high flexibility in terms of the assignment of personnel (service planning) and the option of flexible (shortterm) personnel management and flexible care: nurse:patient ratio. Adjusting treatment to patient needs is straightforward and patients do not need to be transferred if their status changes. This can reduce the loss of information and ensure optimum continuity of treatment. A physician is permanently present. It is not necessary to make two sets of equipment available (ultrasound, ECG, defibrillator, transport ventilator, blood gas analysis [BGA] equipment, etc.). Disadvantages include the cost of basic equipment for each patient bed; the loud and turbulent environment of an ICU for intermediate care patients that are awake; the difficulty of categorising patients as intensive care or intermediate care due to the various influences and interests; and the potential for conflict when it comes to bed allocation on interdisciplinary units. The possible advantage of flexible personnel management can be highly demanding and may also be subject to the influence of various conflicts of interest.

\section{Parallel model on an intensive care unit}

$[7,8]$. ICU and IMC are separated into defined areas with differing facilities, but are adjacent to each other and can access the same resources. Advantages include: the common use of (technical) intensive care resources (ultrasound, ECG, defibrillator, transport ventilator, BGA, etc.); a common administration; the constant presence of readily available physicians; high flexibility in the exchange of nursing personnel between IMC and ICU; unified medical and nursing management with uniform standards and treatment paths; simplified qualification measures for IMC personnel; excellent treatment continuity in the transfer between ICU and IMC with little loss of information; a short transfer distance between IMC and ICU; the possibility of joint monitoring (a single, central office); immediate support from ICU personnel for IMC personnel in medical emergencies; and simplified patient allocation, with unified medical and nursing management and improved admission capacity for intensive care. Possible disadvantages include: the need to move patients between ICU and IMC (transfer to another room); the risk of misallocation of patients on an IMC that should have been treated in an ICU (insidious development of an intensive care situation with a poor personnel:patient ratio); a possible lack of access to certain hospital departments and a possible conflict in bed allocation if intermediate care is interdisciplinary.

Independent intermediate care unit (stand-alone) [7, 8]. This IMC is defined as an independent unit in terms of
Med Klin Intensivmed Notfmed 2018.

113:33-44

https://doi.org/10.1007/s00063-017-0369-7

c) Springer Medizin Verlag GmbH 2017

C. Waydhas · E. Herting · S. Kluge ·

A. Markewitz - G. Marx · E. Muhl - T. Nicolai .

K. Notz · V. Parvu · M. Quintel · E. Rickels .

D. Schneider $\cdot$ K. R. Steinmeyer-Bauer .

G. Sybrecht $\cdot$ T. Welte

Intermediate care units. Recommendations on facilities and structure

\section{Abstract}

A growing number of patients with increasingly complex or specialized diseases are being treated in hospitals worldwide. The treatment requirements of some of these patients are exceeding the capacity of standard nursing units. However, the severity of these diseases or the treatment requirements for these specific clinical pictures do not always justify admission to an intensive care unit. For this reason, an increasing number of special units (intermediate care units) are being set up to offer highly specialized treatment and close monitoring, in order to fulfil an intermediate role between the standard care unit and the intensive care unit. The recommendations of the German Interdisciplinary Association for Intensive Care and Emergency Medicine (DIVI) on the personnel, capacity, equipment and structure of these units are intended to provide the framework for the setting up and operation of intermediate care units in collaboration with experts on both an evidence-based and an expert-based basis (where scientific evidence is not available). Where only minimal or indirect evidence is available, patient safety is paramount in the formulation of the recommendation.

Keywords

Organization - Personnel · Medical staff . Equipment

space, organisation and staff. In addition to its clear structure, consistent treatment paths are seen predominantly as strengths. This model represents a good solution if there are structural restrictions in the ICU. It can also be useful as a specialised treatment unit in buildings without their own ICU. However, it must not be used as a replacement ICU, but rather there should be an agreement with ICUs at other institutions to ensure that patients meeting the criteria for intensive care can be transferred at any 
time. It can be a disadvantage that: there is less flexibility for small units in terms of planning nursing rotas; very small units need to fulfil minimum nursing cover per shift with two nurses present; there may be a lack of continuity in the transition from and to the ICU with loss of information; and personnel may have more difficulty qualifying in intensive care needs. Units of this kind require a full technical infrastructure of their own (ultrasound, ECG, defibrillator, transport ventilation, BGA, etc.). It may be further to transport patients between ICU and IMC, with reduced flexibility in terms of transfers and higher requirements for documentation (e.g. transfer reports, handover protocols).

Integration model in, or parallel model to, a normal unit [7]. On a joint unit, SCU and IMC patients are treated together or in immediately adjacent areas. The formal allocation to one or other category is made using a list of criteria. Advantages include: easier transfer between IMC and SCU; greater incentive for nursing personnel on the SCU to gain higher qualifications; and better and easier control of patient flow in a department with many high-risk patients. Set against this is the risk of lower staff qualifications, especially poor or lacking skills in intensive care nursing; longer transfer distances between IMC and ICU; lack of continuity during transfer between IMC and ICU with loss of information; possibly poorer physician availability and the lack of a designated, continuous unit director; prompt management of emergencies may be hampered and acute patient deterioration may ensue; and finally, difficultto-implement personnel exchanges between IMC and ICU with the possibility of loss of competence over time.

\section{Bed numbers}

\section{Key statement}

Units with $10-12$ beds are recommended for stand-alone IMC wards. An integration or parallel model is preferable for lower bed numbers. Bed requirements should be individually determined for each institution. Structural, organisational and facility requirements must be fulfilled irrespective of bed numbers (1C).

Scientific evidence on medically recommended bed numbers or unit size is not available (this may also depend on the individual organisational form). Predominantly organisational and economic considerations can therefore be used here, as well as the requirements of special patient groups and clinical pictures. The size of the "unit" is not the same as the size of a ward. The latter may be larger and consist of several "units" (see below). However, the required structural, personnel and facility criteria must be fulfilled irrespective of bed numbers.

For patients undergoing cardiac procedures, 0.75 beds per 100 procedures involving a heart-lung machine are recommended [7]. Various different calculation models have been described in a DGAI position paper, although these have not been validated (in [9]). It is not possible to make a generally valid recommendation on the required number of beds. Local requirements must be determined for each institution. For example, the following parameters can be used to calculate requirements.

- Number of patients treated as inpatients in the hospital as a whole

- Disease severity of patients treated as inpatients (e.g. case mix index)

- De-registration or refusal rates due to a lack of ICU beds for surgical procedures, emergency patients, transfers from other hospitals, etc.

- Rates of "mis-allocation" of patients not requiring intensive therapy to ICUs

- Rates of (unplanned) transfer from SCUs back to ICUs due to complications

- Excessive demands (on staff) and undertreatment (of patients) on SCUs
- Where available: deployment of a rapid response team or number of modified early warning score (MEWS)-triggered alarms

- Mortality in the case of selected diagnoses (e.g. sepsis, pneumonia, pancreatitis, coronary infarction, stroke, femoral neck fracture)

At least 10-12 beds are recommended for stand-alone wards $[3,5,6,10]$. It makes little economic sense to equip smaller units with the required structure. If the IMC is linked to another acute medicine department (e.g. parallel model ICU), then bed numbers can be lower $[3,6]$. There is no reliable information on an upper limit for bed numbers in an IMC. Sizes of 22-28 beds have been established. There is a tendency to consider very large units more difficult to manage. Dividing larger units into smaller units of 10-12 beds is recommended. 


\section{Range of services offered by hospitals with an IMC and their (24 h) availability}

\begin{tabular}{|l}
\hline Key statement \\
\hline The following services should be available in \\
hospitals with an IMC (1A): \\
24-Hour availability (presence) \\
- Conventional X-ray \\
- Computer tomography \\
- Bronchoscopy \\
- Ultrasound \\
24-Hour availability on site or as \\
a cooperation model within 30 min \\
- Interventional cardiology diagnosis and \\
$\quad$ therapy \\
- Surgical capacity for emergency proce- \\
$\quad$ dures \\
- Gastroscopy \\
- Blood bank and competence in transfusion \\
$\quad$ medicine \\
- Clinical chemistry laboratory \\
- ICUa \\
Availability within $24 \mathrm{~h}$ (on call or as \\
a cooperation model) \\
- MRI \\
- Angiography/digital subtraction angiog- \\
raphy (DSA) \\
- Neurology \\
- Microbiology \\
- Pharmacy \\
- Hygiene \\
depending on special requirements of the \\
patient collective. \\
aln institutions without an ICU, provision must \\
be made for transfer to an ICU elsewhere. \\
\end{tabular}

\section{Key statement}

In hospitals with an IMC, the following specialist medical expertise must be available (1A):

24-Hour availability (presence)

- Internal medicine

- Surgery

- Anaesthesiology

24-Hour availability (on call within $30 \mathrm{~min}$ )

- Additional specialist presence may be necessary depending on special requirements of the patient collective ${ }^{\mathrm{a}}$

${ }^{\text {a } F o r ~ m o r e ~ d e t a i l s, ~ t h e ~ r e a d e r ~ i s ~ r e f e r r e d ~ t o ~ t h e ~}$ recommendations of specialist societies or certification institutions, e. g. Stroke Units [6, 10-12] or Chest Pain Units [13, 14].

The services maintained by a hospital to ensure safe treatment of adequate qual- ity for severely ill or at-risk patients is based on a medical assessment regarded as equally necessary by numerous national and international specialist societies and committees $[3,6,7,15]$. Falling short of this standard would lead to serious complications-which can be expected in IMC patients and are indeed the rationale behind their monitoring and treatment on an IMC unit-that cannot be treated with the due (specialist) and prompt standard care.

\section{Procedures on the unit}

\section{Key statement}

Regulations for medical rounds, instructions on organisational and uniform medical care (between ICU and IMC) and visiting hours etc., need to be specified in writing (1C).

Both in terms of organisation and medical treatment, an IMC requires clear, consistent and thorough regulations for the smooth running of the unit. This applies to all patients, irrespective of the medical speciality responsible for the treatment of the underlying disease. These regulations cover the entire spectrum of basic care, monitoring of vital functions and general therapies and prophylaxis. Specialist departments treating patients on an IMC need to develop a binding consensus for this. Independently of this, specific medical decisions, particularly those for the treatment of underlying diseases by the treating discipline, must be made in agreement with the medical management of the IMC.

The following regulations in particular need to be set:

- Regular rounds/consultations of all disciplines and professional groups involved in treatment [1]

- Instructions, standard operating procedures (SOPs), algorithms, guidelines or instructions, etc. for organisational and general areas (hygiene plans, provisions, responsibilities, etc.).

- Instructions, SOPs, algorithms, guidelines or instructions, etc. for medical areas (difficult airway management, sedation/delirium, nutrition, non-invasive ventilation (NIV)/ bronchial toilet, the clinical pictures to be treated, frequently performed procedures) [5]

- Regulation of visiting hours

\section{Quality assurance}

\section{Key statement}

Documented and transparent internal quality assurance should be carried out on the IMC, as well as an at least annual report on performance figures and results and, where possible, an external quality assurance (1C).

General criteria or parameters and instruments for an external quality comparison of IMCs have not yet been established. Nevertheless, quality assurance measures as established in medicine in general, and in intensive care medicine in particular, can be carried out. These include (without any claim to exhaustiveness) interdisciplinary and interprofessional case conferences, morbidity and mortality (M\&M) conferences, infection statistics, complication statistics and the collection of process parameters. Peer review can also be carried out on the IMC. With the exception of quality indicators for ventilation, the quality indicators of the Peer Review process in intensive care medicine can also be applied on the IMC.

The basis for this is regular reporting, which should include data on patient numbers, patient flow, treatment measures, cost description (e.g. therapeutic intervention scoring system [TISS]-28, or similar) and other items, in addition to the above information.

External quality and benchmarking instruments have already been established for specific areas $[6,15,16]$.

\section{Special recommendations}

\section{Admission, exclusion and discharge criteria}

\section{Key statement}

The criteria for the admission of patients to an IMC, for transfer from an IMC and for patients who should not be placed on an IMC should be based on the list below (1C). 
The use of criteria for the admission of a patient to an IMC is strongly recommended, as well as criteria on the basis of which they should not be admitted to an IMC, but instead require intensive care treatment. It should also be specified when a patient can be transferred to a SCU and when transfer to an ICU is required. Additional or modified criteria can be defined for specialised IMCs. For units that do not meet the recommended standards, the admission criteria must be modified such that only patients that can be safely cared for with the available resources are admitted. The following criteria are recommended largely as a basis for the development of the relevant list of criteria. This list also represents a basis for setting requirements in terms of structure and equipment for the IMC.

\section{Admission criteria}

General.

- Need for monitoring more than $6 \times /$ day or every $4 \mathrm{~h}$

- Absence of criteria requiring admission to ITS

- Increased need for care

The increased need for care could, e.g. be defined according to the Swiss classification in categories 2 and 3 (in special cases also $1 \mathrm{~A}$ and $1 \mathrm{~B}$, if any of the other criteria below are present) on the basis of the nine equivalents of nursing manpower (NEMS) and the Richmond agitation-sedation scale (RASS) [3]. The nursing activities score (NAS) offers another possibility, although this is not currently widespread in Germany [17-19].

\section{A. Cardiac System.}

- Exclusion of acute myocardial infarction [1]

- Non-ST elevation myocardial infarction, haemodynamically stable [1, 14]

- Arrhythmia, haemodynamically stable [1]

- Haemodynamically stable patient without myocardial infarction, but requiring a temporary cardiac pacemaker [1]

- Acute heart failure without shock (Killip Class I, II) [1]
- Hypertensive emergency without evidence of acute organ damage requiring treatment [1]

\section{B. Respiratory System.}

- Patients with mild respiratory failure or the risk of deterioration of respiratory failure requiring close monitoring and/or intermittent respiratory support (e.g. NIV/continuous positive airway pressure [CPAP]/high flow oxygen) [1]

- Patients who require close checks on vital parameters or intensive respiratory physiotherapy (e.g. tracheal aspiration more often than $3 \times /$ day) [1]

\section{Neurological System.}

- Acute neurological-neurosurgical picture with the need for frequent neurological examination or frequent suctioning of the oral cavity or positioning [1]

- Disoriented patients requiring close monitoring and examination for signs of neurological deterioration [1]

- Stable neurological patients requiring cerebrospinal fluid (CSF) drainage [1]

- Patients with chronic neurological disorders, e.g. neuromuscular disease requiring frequent care measures [1]

\section{Poisonings and Overdoses.}

- Any patient requiring frequent neurological, respiratory or cardiovascular monitoring following poisoning or overdose and that is haemodynamically stable [1]

\section{E. Gastro-intestinal Disorders.}

- Gastro-intestinal bleeding with mild orthostatic hypotension that reacts to volume administration [1]

\section{F. Endocrine System.}

- Diabetic ketoacidosis requiring continuous and constant intravenous insulin administration or more frequent insulin injections in the early phase once ketoacidosis has been controlled [1]
- Hyperosmolar syndrome with increased risk of coma [1]

- Thyrotoxicosis, hypothyroidism requiring close monitoring [1]

\section{G. Surgical Conditions.}

- Postoperative patients following major procedures that are haemodynamically stable but with an increased need for volume and transfusion, caused by large fluid shifts [1]

- Stable postoperative patients but with a high postoperative risk of bleeding (e. g. following mass transfusion, taking anticoagulant therapy, bleeding at the end of the procedure)

- Postoperative patients requiring close nursing care and monitoring, e.g. following carotid endarterectomy, peripheral vessel reconstruction, $\mathrm{V}$-P shunt revision, kidney transplant [1]

H. Other.

- Treated and regressing sepsis without shock or secondary organ failure [1]

- Patients requiring close monitoring of fluid management $[1,20]$

- Obstetric patients during pregnancy or post-partum with (pre)eclampsia or other medical problems [1]

- Any patient requiring frequent monitoring or very complex wound management that does not fall into any of the above categories (e.g. Addisonian crisis, acute renal failure, delirium tremens, hypercalcaemia) [1]

\section{Exclusion criteria}

The following conditions are usually not suitable for admission to an IMC. These should also be locally defined and may vary depending on the equipment on the unit, the experience of the treatment team, the type of patient or the disease condition.

- Acute ST-elevation myocardial infarction, acute coronary syndrome with haemodynamic instability, temporary pacemaker, haemodynamic instability of other cause, pulmonary oedema with the risk of an indication for intubation or the risk of heart rhythm disorders $[1,21]$ 
- High catecholamine requirements or sharply varying/increasing dose, drugs requiring extensive haemodynamic monitoring

- Acute mechanical circulatory support [20]

- Patients with shock (septic, haemorrhagic, cardiogenic, anaphylactic) [20]

- Acute dialysis, continuous renal replacement therapy (CRRT)

- Patients with acute respiratory failure that have recently been intubated or in whom intubation may be required [1]

- Patients with an endotracheal tube

- Patients requiring extensive invasive haemodynamic monitoring (PiCCO, pulmonary artery or right atrial catheter or similar) or cranial pressure measurement $[1,20]$

- Patients in status epilepticus [1]

- Patients with elevated cranial pressure [20], subarachnoid haemorrhage (SAH) with vasospasm [20]

\section{Transfer/discharge criteria}

- If the patient's condition does not require intensive monitoring and treatment is possible on an SCU [1]

- If the patient's condition has deteriorated to the extent that active organ replacement is required or probably required, transfer should be made to the ICU based on a unit-specific protocol [1]
Staffing

\section{Medical personnel (number, qualification, availability)}

\section{Key statement}

A unit director and a deputy should be appointed. The director should be board certified in intensive care and the deputy should be a specialist with at least 1 year's experience in intensive care (1C).

The director or deputy should do daily rounds and visit all patients on the unit at least twice a day on all normal working days (1C).

The continuous presence of a physician is required and may be organised at night and weekends in the form of an on-call service in the hospital. The on-call service must reach the patient within $5 \mathrm{~min}$. The unit physicians (including the on-call service) must know the patients. (1C).

It is essential to ensure that a specialist with knowledge of intensive care can be present on the unit at any time (within $5 \mathrm{~min}$ ) (1C).

The 1998 recommendation that responsibility for the management of an IMC should be taken by an appointed director who is board certified in intensive care [1] has since been unreservedly confirmed by numerous specialist societies and is considered to be medically indispensable. As well as organisational responsibility, the management function also comprises, in particular, specialist monitoring, further education and training of doctors and nurses on the unit. Making bedside visits twice daily represents a minimum requirement for assuming medical responsibility. Continuous specialist monitoring must also be ensured (see below) and should be largely covered by the director and deputy. In the integration model and the parallel models, joint management of intensive care and intermediate care simultaneously is desirable and beneficial. There can be separate managements for stand-alone IMCs, but simultaneous management is also possible, assuming the prerequisites are fulfilled (full-time management of intensive care, twice daily patient rounds on normal working days).

A clearly regulated and appointed deputy with comparable competence is required to compensate for absences due to official trips, holiday and illness, etc. without loss of quality. In all current
Swiss guidelines on the recognition of IMC [3] for appointed deputies, a specialist with 12 months of intensive care training or 6 months of intensive care training plus 6 months of training in emergency admissions or anaesthesia or on an IMC are required. Extrapolated to the German training regulations, this would mean, in addition to specialist physician status, formally verifiable qualification in the form of evidence of board certification in intensive care or board certification in emergency medicine or the anticipated future board certification in clinical emergency medicine.

In the past, a continuous medical presence was not regarded as essential on an IMC [7-9]. However, it is indisputable that there are numerous situations when the presence of a physician is essential [7, 9]. Examples include situations such as the status of a patient less than $2 \mathrm{~h}$ following extubation, during admission and discharge procedures, patients with unstable vital functions and large case numbers. Typical serious complications can occur in particularly at-risk and ill patients on an IMC as a result of acutely deteriorating vital functions or emergencies. The immediate availability of a physician who knows the patient within a maximum of $5 \mathrm{~min}$ is now considered essential $[7,9]$. To ensure this, the IMC physician on duty should not perform any activities that keep him/her out of or away from the IMC even for a short time. S/he must stay on the ward or in the immediate vicinity. The Swiss guidelines require that it must be possible to carry out emergency measures at any time [3]. Certainly, a response time of $5 \mathrm{~min}$ appears relatively long for patients known to be sick and under medical care. It is therefore essential that the IMC physician is also actually continuously present on the ward, is immediately close by or his/her on-call room is in direct proximity to the IMC.

Specialist monitoring must be ensured by a physician with at least 1 year's experience in intensive care in cases where it cannot be performed by the director or deputy (e. g. during on-call times). Continuous specialist monitoring by a physician board certified in intensive care is considered essential $[3,7]$. 
Table 1 Listing of technical equipment required for monitoring and diagnostic procedures

\begin{tabular}{|c|c|c|}
\hline & $\begin{array}{l}\text { Recommen- } \\
\text { dation }^{\mathrm{a}}\end{array}$ & Comment \\
\hline Electrocardiographic/heart rhythm & $1 \mathrm{Ca}$ & - \\
\hline Non-invasive blood pressure measurement & $1 \mathrm{Ca}$ & - \\
\hline Intra-arterial blood pressure measurement & $1 \mathrm{Ca}$ & - \\
\hline Central venous pressure measurement & $1 \mathrm{Ca}$ & - \\
\hline Temperature & $1 \mathrm{Ca}$ & - \\
\hline Pulse oximetry & $1 \mathrm{Ca}$ & - \\
\hline Breathing rate measurement & $2 \mathrm{Ca}$ & - \\
\hline Monitoring with connection to a central point & $1 \mathrm{Ca}$ & - \\
\hline Blood gas analysis & $1 \mathrm{Cs}$ & $\begin{array}{l}\text { Including lactate, glu- } \\
\text { cose, electrolytes }\end{array}$ \\
\hline Arrhythmia monitoring & $\begin{array}{l}2 \mathrm{Ca} \\
\mathrm{FS} 3 \text { and FS2 } \\
\text { (cardiac surgery) } \\
1 \mathrm{Ca}\end{array}$ & - \\
\hline ST analysis & $\begin{array}{l}2 \mathrm{Ca} \\
\mathrm{FS} 3 \text { and FS2 } \\
\text { (cardiac surgery) } \\
1 \mathrm{Ca}\end{array}$ & - \\
\hline Bed scales & $2 \mathrm{Cs}$ & - \\
\hline Mobile 12-lead ECG & $1 \mathrm{Cs}$ & - \\
\hline Transport monitor & $1 \mathrm{Cs}$ & - \\
\hline Bronchoscopy & $1 \mathrm{Cs}$ & - \\
\hline Ultrasound (including Doppler) & $1 \mathrm{Cs}$ & - \\
\hline Transthoracic echocardiography & $1 \mathrm{Cs}$ & - \\
\hline Transoesophageal echocardiography & $\begin{array}{l}\text { FS2 (cardiac } \\
\text { surgery) and } \\
\text { FS3 }\end{array}$ & Available in the hospital \\
\hline Transcranial Doppler, colour duplex ultrasound & Only FS4: 1 Cs & - \\
\hline X-ray equipment, mobile & $1 \mathrm{Cs}$ & - \\
\hline Capnometry & $1 \mathrm{Cv}$ & - \\
\hline Electroencephalography and EVOPS & $\begin{array}{l}\text { FS4: Available in } \\
\text { the hospital }\end{array}$ & - \\
\hline
\end{tabular}

Special requirements must also be fulfilled for specialised IMCs such as Stroke Units. The German [6] and Swiss [10] regulations cited as an example here have comparable validity in other countries and throughout Europe [11, 12]. Using the regional Stroke Units in Germany as an example, management by a neurological or medical specialist, the presence of at least two neurological specialists in the hospital and the assignment of a physician to the Stroke Unit at all times (whose time for other tasks must not exceed 20\% of his total work time) is required. For transregional Stroke Units, management must be by a neurology specialist and there must be a $24 \mathrm{~h}$ medical presence

\section{Nursing personnel (number, qualification)}

\begin{tabular}{l}
\hline Key statement \\
\hline A head nurse and a deputy should be \\
appointed for the unit. The head nurse should \\
have specialist training in intensive care and \\
at least 3 years' working experience on an \\
ICU. The deputy should have at least specialist \\
training in intensive care or intermediate care \\
$(1 C)$. \\
The head nurse should have a clearly defined \\
daily period specifically identified in the \\
roster for administrative and organisational \\
management tasks, during which s/he should \\
not be involved in any patient care tasks (1C). \\
The nurse:patient ratio should be at least $1: 4$. \\
A higher ratio is required for higher treatment \\
requirements. A minimum of two nurses \\
should be present in the unit at all times. At \\
least one nurse with specialist intensive care \\
training should be present during each shift \\
$(1 A)^{a}$. \\
At least $20 \%$ of nurses in the whole team \\
should have training in intensive care. The \\
remaining nursing staff should have training \\
in intermediate care or have passed the \\
nursing examination (1C) \\
a Compliance with this key statement should \\
be achieved on at least $95 \%$ of shifts.
\end{tabular}

There is no doubt among nursing and medical associations that a unit of this high level of specialisation with severely ill patients requiring far more than the possibilities of a normal unit requires a dedicated and competent head nurse. Severely ill patients on an IMC are usually in transition to an ICU, so head nurses require a qualification resulting from further training in intensive care. A minimum of 3 years of working on an ICU is strongly recommended [1]. The head nurse also requires structured time available in order to fulfil administrative, organisational, nursing, medical and instructing tasks. The medical director and the head nurse must be in constant contact. Therefore, sufficient time must be allowed in the job planning and duty roster without duties in patient care [1]. As a guide, units with 12 beds or more are assumed to be a full-time position (without working in patient care).

A deputy head nurse is needed for times of absence. Their qualifications should be sufficiently high to allow no reduction in quality. 
A ratio of one nurse to four patients (1:4) is required to cover patients that meet the admission and transfer criteria for an IMC. There is evidence of a clear association between nurse:patient ratios and morbidity and mortality for ICUs, where a ratio of less than 1:2 was associated with a poorer result. It is highly probable that a similar association also exists for IMCs and corresponds with the experiences of most IMC operators. Generally, the ratio of 1:4 is regarded as the minimum requirement for IMC by a wide variety of medical societies in a large number of countries $[5,8,15$, 23]. Numerous medical societies consider a nurse:patient ratio of $1: 3$ to be necessary $[7,8,15,22,23]$, depending in part on the severity of the disease or the time of day $1: 2[7,8,15]$.

In some models, e.g. Switzerland, a flexible nurse:patient ratio is promoted, depending on the severity of the disease and nursing costs [3]. As a supplement to the Swiss calculation model, other calculation systems for patient-dependent nursing staff requirements according to patient numbers have been suggested $[24,25]$. Such highly flexible personnel requirements (changing from day to day, sometimes hour to hour) are difficult to implement, so it may be assumed that, with bed allocation consistent with the above admission criteria, there is an averagely even distribution of nursing staff, chiefly depending on bed allocation. However, prior commitments must always be taken into account.

It has been shown in Great Britain that the nurse:patient ratio was on average 1:3 across the country and worse than 1:4 in only $16 \%$ of IMCs [26]. It was also shown that using a TISS- 28 of on average 23 and a nursing dependency score of on average 1.0 , cover of at least 1:2 would have been required [27].

By nurses, one means a fully qualified nurse [3], as a minimum requirement for care of such severely ill patients. Personnel with lower qualifications are not regarded as sufficiently competent to ensure the safety of patients to the required extent. We recommend using only nurses with at least 1 year of professional experience [9]. A specific requirement profile has been defined for
IMC nurses [2]. A rotation of nurses between intensive care and intermediate care is recommended as highly desirable and as an approach to staff qualification and personal development.

At least one nurse with specialist intensive care training should be present during each shift. Compliance with this cover should be achieved on at least 95\% of shifts. For specialised patient groups, e. g. on the stroke unit, additional qualifications may be required $[3,6]$.

Furthermore, at least $20 \%$ of nursing positions in the team should be covered by nurses with specialist training in intensive care.

Specialist training in intermediate care is now being recommended by the German Hospital Association, which may contribute to an increase in specialist competence in nursing. However, this does not replace a basic component (see above) of nursing competence with specialist training in intensive care.

It is recommended that staff positions for mentors for specialist training should be budgeted for $[9,22]$. The greatest challenge for IMCs in the coming years will be the funding of the next generation nurses and commitment to one's own establishment.

\section{Physiotherapy}

\section{Key statement}

Physiotherapy should be available every day (including weekends and public holidays) (1C).

Physiotherapy is a key component of the treatment of critically ill patients [1]. At a minimum, physiotherapy should be provided on at least 5 out of 7 days [5]. Whether this is actually sufficient is regarded critically, and daily physiotherapy is considered essential by the majority of authors $[6,7,10,15]$. There is evidently no basis in medical argumentation for two or sometimes more days without physiotherapy. Integrating physiotherapists into the care team may be beneficial [3].

\section{Other personnel}

\section{Key statement}

Additional posts should be made available for non-patient-related activities (logistics, ordering systems, patient transport, telephone service/office work) (1A)

\section{Key statement}

The following personnel functions should be available $24 \mathrm{~h}$ a day $(1 \mathrm{~A})$ :

- Cleaning staff

- Specialist personnel (e. g. cardio technicians, respiratory therapists) depending on specific diseases, insofar as the relevant tasks cannot be taken on by nursing staff

\section{Key statement \\ The following personnel functions should be available on weekdays at least $(1 \mathrm{~A})$ : \\ - Social services \\ - Hygiene officer \\ - Clinical pharmacy \\ - Psychologist \\ - Logotherapy/swallowing therapy ${ }^{a}$ \\ - Ergotherapy ${ }^{\mathrm{a}}$ \\ - Unit secretary \\ - Support staff (logistics, ordering systems, etc.) \\ The following staff functions are desirable \\ (2C): \\ - Nutritional advice \\ - Care assistant \\ aRequired for specific diseases/IMC criteria.}

Medical and nursing personnel must be supplemented by other professional groups and staff in terms of work sharing, competence and responsibility, as well as smooth and safe functioning of the unit. Comprehensive recommendations were made on this by the American College of Critical Care Medicine [1] and are equally valid for Germany [9, 22].

Regular support of the IMC by a clinical pharmacy, a clinical pharmacologist or as part of an Antibiotic Stewardship is urgently recommended [1]. An investigation of a before and after comparison on a coronary care unit showed that the drug costs per admission could be significantly lowered from US\$374.05 to US $\$ 233.0$ by including a clinical pharmacist. The greatest portion of this saving was on sedatives, oral use of antibiotics, 
Table 2 Listing of technical equipment required for therapeutic measures, procedures or interventions

\begin{tabular}{|c|c|c|}
\hline & $\begin{array}{l}\text { Recommen- } \\
\text { dation }^{\mathrm{a}}\end{array}$ & Comment \\
\hline Oxygen Insufflation & $1 \mathrm{Ca}$ & - \\
\hline Resuscitation bag & $1 \mathrm{Cv}$ & - \\
\hline Non-invasive Ventilation equipment & $1 \mathrm{Cv}$ or s & $\begin{array}{l}\text { Number depending on } \\
\text { organisation, including } \\
\text { a range of interfaces }\end{array}$ \\
\hline High-flow oxygen administration & $2 \mathrm{Cs}$ & - \\
\hline Transport respirator & $1 \mathrm{Cs}$ & - \\
\hline Equipment for inhalation therapy & $1 \mathrm{Cv}$ & - \\
\hline Airway suction equipment & $1 \mathrm{Cv}$ or a & - \\
\hline Equipment for physical respiratory therapy & $1 \mathrm{Ca}$ or v & - \\
\hline Equipment for enteral nutrition & $1 \mathrm{Cv}$ & - \\
\hline Infusion and injection pumps & $1 \mathrm{Ca}$ & $\begin{array}{l}\text { Per bed } \\
1-2 \text { infusion pumps } \\
3-4 \text { injection pumps }\end{array}$ \\
\hline Emergency equipment & $1 \mathrm{Cs}$ & - \\
\hline Defibrillator & $1 \mathrm{Cs}$ & - \\
\hline External cardiac pacemaker & $1 \mathrm{Cs}$ & - \\
\hline Cooling/warming procedure for patients & $1 \mathrm{Cv}$ & Available in hospital \\
\hline Suction device (for chest drainage, etc.) & $1 \mathrm{Cv}$ & - \\
\hline $\begin{array}{l}\text { Special beds (e. g. for decubitus prophylaxis or } \\
\text { therapy, heavy duty beds) }\end{array}$ & $1 \mathrm{Cv}$ & $\begin{array}{l}\text { Do not need to be avail- } \\
\text { able but must be deliv- } \\
\text { ered promptly }\end{array}$ \\
\hline Mobilisation aids & $1 \mathrm{Cs}$ & - \\
\hline
\end{tabular}

Table 3 Discription of the level of recomemendation accordung to the criteria by Guayatt et al [30]

1 A Strong recommendation

1B Strong recommendation

1C Strong recommendation

2A Weak recommendation

2B Weak recommendation

2C Weak recommendation
High quality evidence, high quality RCTs, very strong data from observational studies, legal situation

Good evidence, RCTs with limitations, strong data from observational studies

Weak evidence, observational studies, case series, expert opinion

High quality evidence, high quality RCTs, very strong data from observational studies

Good evidence, RCTs with limitations, strong data from observational studies Weak evidence, observational studies, case series, expert opinion
Unlimited application to most circumstances

Unlimited application to most circumstances

Could change if better evidence becomes available

Can depend on circumstances, patients, social values

Can depend on circumstances, patients, social values

Very weak recommendation, other alternatives could be equally beneficial

\section{Monitoring and diagnosis}

The equipment given in $\bullet$ Table 1 should be available. Numerous existing recommendations have been taken into account in the present recommendation $[3,5-7$, $9,15]$. An explanation of the recommendation coding can be found in the "Methods" section.

\section{Treatment}

The equipment given in $\bullet$ Table 2 should be available. Numerous existing recommendations have been taken into account in the present recommendation $[3,5-7$, $9,15]$. An explanation of the recommendation coding can be found in the in the "Methods" section.

\section{Spatial configuration}

The recommendations for spatial setup and configuration contain some generally valid recommendations, and some rules and regulations have been taken into account that may be specific to Germany (e.g. DIN specifications). The full recommendations on spatial configuration can be seen on the DIVI homepage (http://www.divi.de/ empfehlungen/imc-entwurf.html).

\section{Methods}

Advice on methodology was provided by Christoph Mosch, Institute of Research in Surgical Medicine (IFOM) at Witten/Herdecke University, Ostmerheimer Str. 200, 51069 Cologne, eMail: christoph.mosch@uni-wh.de.

\section{Literature search}

The Summary of Abstracts was a systematic overview of all relevant publications (01 January 1990 up to 27 June 2014) that provide information on the structural/ organisational/structural requirements and staff/technical equipment for patient care on IMCs, i. e. transition wards between ICU and follow-up treatment on an SCU. The literature search was repeated with the same criteria for the period from 28 June 2014 to 22 November 2015. Recommendations were also sought from German, European and 
Table 4 Type, strength and scope of appli-

cation of the recommendations on technical equipment

1C Urgently required basic structure and basic equipment

2C Strongly recommended structure and equipment

FS Specifically required structure and equipment (5 specialities)

FS1 Anaesthesia

FS2 Surgery (general and visceral surgery, cardiac surgery, thoracic surgery, orthopaedics and trauma surgery, burns medicine, transplant surgery)

FS3 Internal medicine

FS4 Neuromedicine (neurology, neurosurgery)

FS5 Paediatric and adolescent medicine including neonatology

a Permanently available at all beds

v Available on the unit and promptly or immediately deployable at all beds

s At least one device/article available on the unit ready for use

North American specialist societies that treat patients in IMCs and ICUs.

\section{Approach to study identification and selection}

To obtain a global view of the question, the search was extended to weaning units, post-operative monitoring rooms and Stroke Units. Paediatric IMCs were also included in the Summary of Abstracts (without neonatology).

After establishing the inclusion criteria (see Appendix 2, Electronic supplementary material) and creating a research strategy (see Appendix 3, Electronic supplementary material) in cooperation with the clinical contact, the systematic literature research was carried out in two electronic databases (MEDLINE [using PubMed] and EMBASE). The publications identified were checked by two independent colleagues for title/level of abstract for their fulfilment of all inclusion criteria. Where there were deviations, a consensus was found by discussion of each abstract regarding inclusion or exclusion. Similarly, all publications included at the abstract level were checked and thematically grouped in the full text by two colleagues working independently of each other.

\section{Results}

After carrying out the systematic search on 27 May 2014, a total of 911 potentially relevant publications were identified (after eliminating duplicates). In the title/ abstract screening, a total of 73 publications were included and checked in the full text. A total of 23 full texts were used as the basis for evidence (see flow chart). For the supplementary period of the second research, three publications were checked in the full text, of which one was used as the basis for evidence.

\section{Consensus finding}

A first draft was compiled by one of the authors (C. W.) based on the identified sources. This was discussed and consented in two Delphi rounds, one consensus conference (16 June 2016) and a final Delphi round on 19 February 2017. The authors comprised DIVI representatives from five DIVI specialities (anaesthesia, surgery, internal medicine, neuromedicine, paediatrics), from nursing as well as structural advisers.

The recommendations were then submitted to the DIVI committee. This approved the recommendations unanimously on 07 March 2017 and published the extended version on its internet presence (http://www.divi.de/ empfehlungen/imc-entwurf.html).

\section{Evidence evaluation and level of recommendation}

The level of recommendation was set according to the criteria by Guayatt et al. ([30]; - Table 3).

The recommendations on technical equipment (• Table 4) were discussed under the following plan, since virtually no study data exists for this.

\section{Corresponding address}

\section{Prof. Dr. C. Waydhas}

Chirurgische Universitätsklinik und

Poliklinik, Berufsgenossenschaftliches

Universitätsklinikum Bergmannsheil

Bürkle-de-la-Camp-Platz 1, 44789 Bochum,

Germany

christian.waydhas@bergmannsheil.de
Acknowledgements. We would like to thank Dr. U. Dennler from the Division Manager Medical Controls of Jena University Hospital for reviewing the manuscript and his valuable input.

Conflict of interest. K.R. Steinmeyer-Bauer: At the time of joining the authors in 2014 to April 2016, Dr. Steinmeyer-Bauer was visiting researcher at the Department of Anaesthesiology, focussing on surgical intensive care medicine CCM/CVK, Charité-Universitätsmedizin Berlin. At the same time, he was working, and still works, for VAMED Management and Service $\mathrm{GmbH}$ Deutschland. The unanimous assessment of the authors was that there was no conflict of interest resulting from his activity that had any influence on the declared recommendations. E. Herting states that there are no conflicts of interest related to this publication. He reports grants and personal fees from Chiesi and Dräger, outside the submitted work. $G$. Marx reports grants and personal fees from BBraun Melsungen $\mathrm{GmbH}$, grants and personal fees from Adrenomed, grants and personal fees from Biotest. G. Marx is DIVI and DGAI Board member and Coordinator of AWMF S3 Guideline on volume therapy. C. Waydhas, S. Kluge, A. Markewitz, E. Muhl, T. Nicolai, K. Notz, V. Parvu, M. Quintel, E. Rickels, D. Schneider, G. Sybrecht and T. Welte declare that they have no competing interests.

\section{References}

1. Nasraway SA et al (1998) Guidelines on admission and discharge for adult intermediate care units. American College of Critical Care Medicine of the Society of Critical Care Medicine. Crit Care Med 26:607-610

2. Stacy KM (2011) Progressive care units: different but the same. Crit Care Nurse 31:77-83

3. Schweizerische Gesellschaft für Intensivmedizin (2012) Schweizerische Richtlinien für die Anerkennung von Intensive-Care Units. http://www.sgissmi.ch/index.php/imc.html. Accessed $22 \mathrm{Nov}$ 2015

4. Deutsche Interdisziplinäre Vereinigung für Intensiv- und Notfallmedizin (2010) Empfehlungen zur Struktur und Ausstattung von Intensivstationen. http://www.divi.de/images/Dokumente/ Empfehlungen/Strukturempfehlungen/2011_ StrukturempfehlungLangversion.pdf. Accessed 22 Nov 2015

5. Bingold TM et al (2014) Modulares Zertifikat Intensivmedizin der DGAI. Anästh Intensivmed 55:316-329

6. Deutsche Schlaganfallgesellschaft (2015) Zertifizierungskriterien 2015 - Regionale und überregionale Stroke Units. http://www.dsginfo.de/images/stories/DSG/PDF/StrokeUnits/ SU-Zertifizierungskriterien-2015.pdf. Accessed 22 Nov 2015

7. Markewitz A et al (2012) Empfehlungen der Deutschen Gesellschaft für Thorax-, Herz- und Gefäßchirurgie zur personellen, infrastrukturellen und apparativen Ausstattung einer herzchirurgischen Intermediate-Care-Station. Z Herz Thorax Gefäßchir 26:48-55

8. Cheng DC, Byrick RJ, Knobel E (1999) Structural models for intermediate care areas. Crit Care Med 27:2266-2271

9. Bause $\mathrm{H}$ et al (2002) Intermediate care: Entwicklung, Definition, Ausstattung, Organisation und mögliche Lösungen. Anästh Intensivmed 43:536-541 
10. Matis GK, Chrysou OI, Birbilis TA (2013) Organizational issues in stroke treatment: the Swiss paradigm - stroke units. J Neurosci Rural Pract 4:S131-S133

11. Kaste $M$ et al (2000) Organization of stroke care: education, stroke units and rehabilitation. European Stroke Initiative (EUSI). Cerebrovasc Dis 10(Suppl 3):1-11

12. Thijs V et al (2009) Organisation of inhospital acute stroke care and minimum criteria for stroke care units. Recommendations of the Belgian Stroke Council. Acta Neurol Belg 109:247-251

13. Post F et al (2015) Criteria of the German Society of Cardiology for the establishment of chest pain units: update 2014. Clin Res Cardiol 104:918-928

14. Post $F$ et al (2015) Kriterien der Deutschen Gesellschaft für Kardiologie - Herz- und Kreislaufforschung für "Chest Pain Units". Update 2015. Kardiologe 9:171-181

15. Deutsche Gesellschaft für Pneumologie (2015) Erhebungsbogen zur Zertifizierung von Weaningzentren. http://www.pneumologie.de/ fileadmin/pneumologie/downloads/Aktuelles/ Erhebungsbogen_zur_Akkreditierung_von Weaning-Zentren.pdf?cntmark. Accessed 22 Nov 2015

16. Bingold TM et al (2013) Entwöhnung von der Beatmung. DGAl-Zertifizierung anästhesiologische Intensivmedizin. Anästh Intensivmed 54:522-534

17. Goncalves LA, Padilha KG, Cardoso Sousa RM (2007) Nursing activities score (NAS): a proposal for practical application in intensive care units. Intensive Crit Care Nurs 23:355-361

18. Lucchini A et al (2014) Nursing Activities Score (NAS): 5 years of experience in the intensive care units of an Italian University hospital. Intensive Crit Care Nurs 30:152-158

19. Padilha KG et al (2010) Nursing workload and staff allocation in an intensive care unit: a pilot study according to Nursing Activities Score (NAS). Intensive Crit Care Nurs 26:108-113

20. Kopp Ret al (2012) Intensive care and intermediate care under a single roof. Anästh Intensivmed 53:698-608

21. Steg PG et al (2012) ESC Guidelines for the management of acute myocardial infarction in patients presenting with ST-segment elevation. Eur Heart J33:2569-2619

22. Deutsche Gesellschaft für Fachkrankenpflege (2010) Stellungnahme der Deutschen Gesellschaft für Fachkrankenpflege und Funktionsdienste e. V. zur Intermediate Care (IMC). http://wordpress. p133885.webspaceconfig.de/wp-content/ uploads/DGF_Stellungnahme_Intermediate_ Care_2010.pdf. Accessed 22 Nov 2015

23. Annonymus (2013) Nurse staffing ratios. AORN J 97:604, 538

24. Farnham JA, Maez-Rauzi V, Conway K (1992) Balancing assignments: a PCS for a step-down unit. Nurs Manage 23:49-50, 52

25. Adomat R, Hewison A (2004) Assessing patient category/dependence systems for determining the nurse/patient ratio in ICU and HDU: a review of approaches. J Nurs Manag 12:299-308

26. Shakir T, Toosy N, Ridley S (1999) A survey of adult general high dependency units in the United Kingdom. Clin Intensive Care 10:219-226

27. Garfield M, Jeffrey R, Ridley S (2000) An assessment ofthestaffinglevel requiredforahigh-dependency unit. Anaesthesia 55:137-143

28. Gandhi PJ et al (2001) Impact of a pharmacist on drug costs in a coronary care unit. Am J Health Syst Pharm 58:497-503
29. Evans RS et al (2015) Use of computer decision support in an antimicrobial stewardship program (ASP). ApplClin Inform 6:120-135

30. Guyatt $G$ et al (2006) Grading strength of recommendations and quality of evidence in clinical guidelines: report from an american college of chest physicians task force. Chest 129:174-181

\section{Lohfert-Preis 2018}

Die Christoph Lohfert Stiftung lobt zum Ausschreibungsthema Kulturwandel im Krankenhaus: Multidimensionale Konzepte zur Verbesserung der (Patienten-)Sicherheitskultur den LohfertPreis 2018 aus. Die Senatorin für Gesundheit und Verbraucherschutz der Freien und Hansestadt Hamburg, Cornelia PrüferStorcks, übernimmt die Schirmherrschaft für den mit 20.000 Euro dotierten För-

\section{derpreis.}

Prämiert werden im Jahr 2018 erneut praxiserprobte und nachhaltige Konzepte, die den stationären Patienten im Krankenhaus, seine Bedürfnisse und Interessen in den Mittelpunkt rücken. Gesucht werden Konzepte und Projekte, die bereits in der Medizin implementiert sind. Diese sollen grundlegend neue Ansätze und patientenorientierte, qualitätsverbessernde Impulse beinhalten. Ziel ist ein Kulturwandel zur Verbesserung der Sicherheitskultur, die bei der Patientenversorgung eine zentrale Rolle spielt. Erwünschte sicherheitsbezogene Grundmuster, geteilte Werte, Überzeugungen und Handlungsweisen bei den Mitarbeitern sollen gefördert und verankert werden. Hierzu sind multidimensionale Ansätze gefragt. Sie sollen die nachhaltige Verbesserung der (Patienten-) Sicherheitskultur in einzelnen Fachabteilungen oder der gesamten Einrichtung fördern.

\section{Bewerbungskriterien:}

Bewerben können sich alle Teilnehmer der stationären Krankenversorgung im deutschsprachigen Raum sowie Management- und Beratungsgesellschaften, Krankenkassen oder sonstige Experten. Die Bewerbung muss in deutscher Sprache verfasst und online eingereicht werden. Bewerbungen werden ausschließlich über das Online-Bewerbungsformular unter www.christophlohfert-stiftung.de angenommen. Informationen und Bewerbungsunterlagen finden sich ebenfalls dort.

\section{Bewerbungsschluss ist der}

28. Februar 2018.

Die Christoph Lohfert Stiftung verleiht den Lohfert-Preis 2018 am 19. September 2018 im Rahmen des 14. Gesundheitswirtschaftskongresses in Hamburg. 